\title{
Analysis of extreme rainfall in Barcelona using a microscale rain gauge network
}

\author{
M. Carmen Casas, ${ }^{a *}$ Raül Rodríguez ${ }^{\mathrm{a}}$ and Ángel Redaño ${ }^{\mathrm{b}}$ \\ a Department of Physics and Nuclear Engineering, EPSEVG, Polytechnic University of Catalonia, Victor Balaguer s/n, O8800 Vilanova i la \\ Geltrú, Spain \\ b Department of Astronomy and Meteorology, University of Barcelona. Av. Diagonal, 647, 08028 Barcelona, Spain
}

\begin{abstract}
Extreme storms registered by the urban rain gauge network installed and supported by CLABSA (Clavegueram de Barcelona S. A.) in Barcelona in the period 1994-2001 have been investigated. Eleven rain events presenting intensities for durations between $5 \mathrm{~min}$ and $24 \mathrm{~h}$ with return periods equal to or larger than 5 years for any of the network gauges have been found. A cluster analysis has yielded four main classes of extreme rainfall events in this area, related to the meteorological scales involved: local (18\%), mesoscale (37\%) and synoptic storms (27\%), as well as more complex rain events originated by multiscale mechanisms acting together (18\%). An intensity index to classify extreme rainfall events in order to their complexity and severity, taking into account the contribution of the different scales implied in the rainfall processes, has been calculated. The frequency distribution of the intensity index values obtained for the urban network has resulted very similar to that calculated for rain data recorded by the Jardí gauge of the Observatory Fabra of Barcelona during 1927-1992 inclusive. Copyright (C) 2009 Royal Meteorological Society
\end{abstract}

KEY WORDS rain gauge network; extreme rainfall; storm classification

Received 8 March 2009; Revised 17 June 2009; Accepted 6 August 2009

\section{Introduction}

The relationship between the maximum rainfall amounts registered in time intervals of different durations for the same rainfall event is very important in certain applications, as the planning of the sewer network of a city or the design of civil engineering works (Sumner, 1978; Eicher, 1991), as well as providing information about the fine structure and the spatial and temporal organization of the rainfall, and, therefore, its origin. Some studies (Lorente and Redaño, 1991; Krajewski et al., 2003; Villarini et al., 2008) have been dedicated to this issue, due to the importance of this information in the investigation of the origin and evolution of the meteorological rainfall situation. Casas et al. (2004) investigated the relationship between the maximum rainfall rate values for time intervals from $5 \mathrm{~min}$ to $24 \mathrm{~h}$ in order to classify the extremely intense events recorded in Barcelona between 1927 and 1992.

In the work of Casas et al. (2004) 44 extreme rain events were selected from series of true maximum rainfall amounts in different time intervals registered by a Jardí gauge (Burgueño et al., 1987, 1994) located in the Observatori Fabra of Barcelona during the period 1927-1992. These events, showing rainfall amounts

\footnotetext{
* Correspondence to: M. Carmen Casas, Department of Physics and Nuclear Engineering, EPSEVG, Polytechnic University of Catalonia, Víctor Balaguer s/n, 08800 Vilanova i la Geltrú, Spain.

E-mail: m.carmen.casas@upc.edu
}

with return periods equal to or longer than 5 years in any of the considered durations between 5 min and $24 \mathrm{~h}$, were characterized and classified into four clearly differentiated groups reflecting the contribution of local, mid and synoptic scale processes respectively in the origin of the rainfall. In addition, the use of an intensity index, IP, (Casas et al., 2004) taking into account the maximum rainfall rate registered for every storm in four characteristic durations ( $5 \mathrm{~min}, 1,2$ and $24 \mathrm{~h}$ ) was suggested.

In order to compare the results obtained from rain data registered only by rain gauge with those calculated using data from a network, in the present work the study of Casas et al. (2004) has been extended to the intense storms registered between 1994 and 2001 by the urban rain gauge network installed and supported by CLABSA (Clavegueram de Barcelona S. A.), a company that controls the sewer systems of Barcelona (Lorente and Redaño, 1990; Enjamio et al., 2005). The method of classification using the clusters analysis has been applied and the IP has also been calculated. The values obtained for this index are distributed in a very similar way to those obtained by Casas et al. (2004).

\section{Analysis of the extreme rainfall registered by the microscale rain gauge network of Barcelona}

The urban area of Barcelona (100 $\mathrm{km}^{2}$ approximately) has a dense network of 23 high resolution tipping bucket 


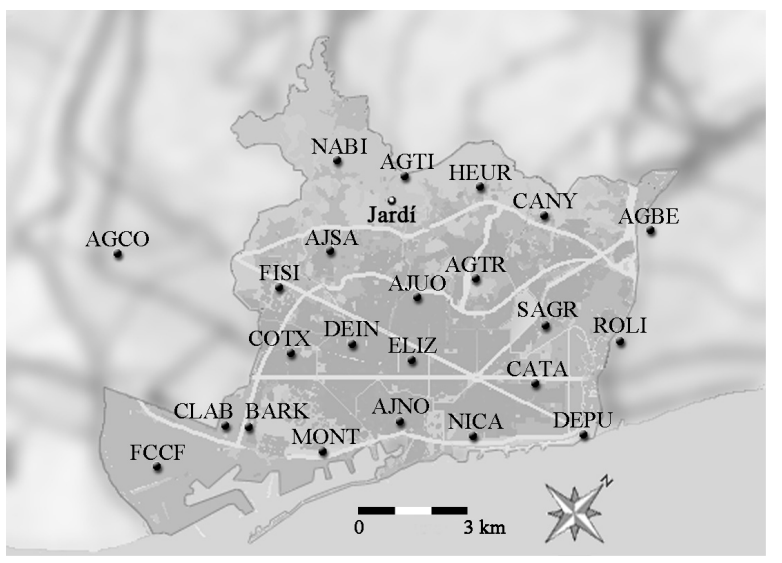

Figure 1. Microscale rain gauge network supported by CLABSA in Barcelona. The position of the Fabra observatory is marked as Jardí.

Table I. Microscale rain gauge network supported by CLABSA in Barcelona.

\begin{tabular}{|c|c|c|c|}
\hline \multicolumn{2}{|c|}{ Rain gauge } & \multicolumn{2}{|c|}{$\begin{array}{l}\text { Location (UTM) } \\
\text { (m) }\end{array}$} \\
\hline AGBE & AGBAR-Besòs & 432572 & 4590189 \\
\hline AGCO & AGBAR-Cornellà & 422530 & 4579549 \\
\hline AGTI & AGBAR-Tibidabo & 426690 & 4586494 \\
\hline AGTR & AGBAR-Turó de la Rovira & 430034 & 4585878 \\
\hline AJNO & $\begin{array}{l}\text { Ajuntament, edifici } \\
\text { novíssim }\end{array}$ & 431351 & 4581678 \\
\hline AJSA & $\begin{array}{l}\text { Ajuntament, Sarrià-Sant } \\
\text { Gervasi }\end{array}$ & 426648 & 4583627 \\
\hline AJUO & Ajuntament, Plaça Lesseps & 429270 & 4584410 \\
\hline BARK & Escola Barkeno & 428485 & 4578698 \\
\hline CANY & $\begin{array}{l}\text { Centre Pau Casals } \\
\text { (Canyelles) }\end{array}$ & 430181 & 4588414 \\
\hline CATA & Escola Catalònia & 433279 & 4585023 \\
\hline CLAB & CLABSA & 427987 & 4578247 \\
\hline COTX & Cotxeres de Sants & 427879 & 4580946 \\
\hline DEIN & $\begin{array}{l}\text { Dipòsit Escola Industrial } \\
\text { (Remota) }\end{array}$ & 428911 & 4582279 \\
\hline DEPU & Depuradora Besòs & 435184 & 4584975 \\
\hline ELIZ & Casa Elizalde & 430373 & 4583077 \\
\hline $\mathrm{FCCF}$ & FCC-Zona Franca & 427443 & 4576149 \\
\hline FISI & Facultat de Físiques & 426341 & 4582030 \\
\hline HEUR & $\begin{array}{l}\text { Palau de les Heures (F. } \\
\text { Bosch i Gimpera) }\end{array}$ & 428357 & 4587775 \\
\hline MONT & Castell de Montjuic & 430431 & 4579649 \\
\hline NABI & Escola Nabi (Vallvidrera) & 425042 & 4585529 \\
\hline NICA & Poliesportiu Nova-Icària & 433035 & 4582822 \\
\hline ROLI & $\begin{array}{l}\text { Ronda Litoral Tram 9, Sant } \\
\text { Andreu }\end{array}$ & 434117 & 4587439 \\
\hline SAGR & Centre Cívic Sagrera & 432334 & 4586332 \\
\hline
\end{tabular}

rain gauges (Figure 1, Table I). The rain gauges (Geónica S. A) have a collector funnel of area $400 \mathrm{~cm}^{2}$ and a resolution of $0.1 \mathrm{~mm}$. The integration time is $1 \mathrm{~min}$ and no correction has been applied to the data supplied by the equipment, since the curve of calibration of the instruments has not been provided by the manufacturer. Therefore, the maximum intensities calculated for durations shorter than $1 \mathrm{~h}$ could have been affected by an error of 10\% (Lanza et al., 2006; Sevruk et al., 2009), whereas for durations longer than $2 \mathrm{~h}$ the error determining the intensity is generally smaller than $5 \%$.

The complete records of 17 rain gauges from 1994 and 22 from 1996 onwards are available. From the rain data recorded, the true maximum rainfall amounts, i.e. the maximum amounts determined from time intervals unrestricted by fixed beginning or ending times (WMO, 1986), registered in Barcelona for durations between $5 \mathrm{~min}$ and $24 \mathrm{~h}$ in the period 1994-2001 have been calculated. Storms showing rainfall rates with return period equal to or longer than 5 years for any of the durations considered between $5 \mathrm{~min}$ and $24 \mathrm{~h}$ have been selected. Table II shows the 45 cases selected, corresponding to 11 actual rainfall events, most of them being registered with amounts up to the threshold considered by more than one gauge. The rainfall events selected are: 29 September and 19 October, 1994 (290 994 and 191 094); 24 August and 21 September 1995 (240895, 210995); 7 August and 13-14 October 1996 (070896 and 141096); 2 and 3 December 1998 (031298), 3 and 13-14 September 1999 (030 999 and 140 999); 15 July and 9 October 2001 (150701 and 091001 ).

For all of the 45 rain cases selected, the IP proposed by Casas et al. (2004) has also been calculated. This index considers the extreme and severe behaviours of the storms, and is defined as (1):

$$
\begin{aligned}
I P(T)= & \frac{1}{4}\left\{\frac{I_{5}}{I(5, T)}+\frac{I_{60}}{I(60, T)}+\frac{I_{120}}{I(120, T)}\right. \\
& \left.+\frac{I_{1440}}{I(1440, T)}\right\}
\end{aligned}
$$

The IDF generalized equation used in this work for Barcelona (2) has been obtained by Casas et al. (2004):

$$
I(t, T)=\frac{19 \log T+23}{(13+t)^{0.87}}
$$

with $I(t, T)$ being the IDF generalized equation of the site of interest (duration $t$ in minutes and return period $T$ in years), and $I_{t}$ the registered maximum intensity for every storm and $t$ duration. Table III shows the index calculated for the return period of 5 years.

The IP reflects the severity of the registered rainfall taking into account the contribution of the different meteorological scales in the origin of the storm. The highest values of this index are reached usually in storms presenting high rainfall intensities for each of the time intervals corresponding to every meteorological scale, even though a singular storm could have a high IP for the extraordinary contribution of an only meteorological scale.

Due to their spatial and temporal characteristics, three of the 11 rainfall events selected show a clear synoptic behaviour, 29 September 1994 (290994), 14 October 1996 (141 096) and 3 December 1998 (031 298), being registered intensities with return period higher than 
Table II. Maximum rainfall precipitation (in $\mathrm{mm}$ ) registered in durations from 5 to $1440 \mathrm{~min}(24 \mathrm{~h})$ for every of the selected extreme rainfall cases.

\begin{tabular}{|c|c|c|c|c|c|c|c|c|c|c|c|c|c|c|c|c|c|}
\hline Gauge & DDMMYY & 5 & 10 & 15 & 20 & 25 & 30 & 35 & 40 & 45 & 50 & 55 & 60 & 120 & 360 & 720 & 144 \\
\hline CANY & 290994 & 3.0 & 4.7 & 6.3 & 8.0 & 10.1 & 12.2 & 13.9 & 15.0 & 16.3 & 17.4 & 18.6 & 19.7 & 35.1 & 82.5 & 82.5 & \\
\hline & & & & 8.1 & 10.6 & 13.1 & & 17.6 & 19.3 & 20.5 & 22.0 & 23.6 & 24.9 & & & & \\
\hline DTX & 1094 & .7 & 13.1 & 19.4 & 25.0 & 29.1 & 33.4 & 36.2 & 38.1 & 40.7 & 43.1 & 43.9 & 45.2 & 63.2 & 71.7 & 71.7 & \\
\hline & & .7 & & & 17.7 & 19.8 & & & 28.5 & & & & & & & & \\
\hline AJNO & 240895 & 11.7 & 21.3 & 29.1 & 37.9 & 46.5 & 54.3 & 60.7 & 66.8 & 73.9 & 78.1 & 79.5 & 80.7 & 94.2 & 131.3 & 133.1 & 133 \\
\hline AJNO & 210995 & 11.4 & 19.9 & 26.3 & 34.6 & 41.3 & 46.3 & 48.6 & 50.3 & 51.2 & 51.7 & 52.1 & 52.6 & 54.6 & 55.3 & 5.3 & \\
\hline & & & & 46.3 & 53.0 & 59.6 & & 69.6 & 72.5 & 74.4 & 75.6 & 76.1 & 79.7 & & & & \\
\hline OTX & 2109 & 9.6 & 15.6 & 24.9 & 30.8 & 39.5 & 45.4 & 47.0 & 47.6 & 49.5 & 50.8 & 51.5 & 51.8 & 53.9 & & 55.0 & \\
\hline SAGR & 210995 & 8.7 & 15.7 & 22.1 & 28.1 & 34.2 & 40.7 & 47.4 & 53.8 & 59.7 & 66.0 & 72.2 & 77.9 & 89.3 & 89.4 & 89.4 & \\
\hline CLAB & 070896 & 19.4 & 25.6 & 27.6 & 28.8 & 29.8 & 31.3 & 31.7 & 32.0 & 32.4 & 32.5 & 32.6 & 32.6 & 32.6 & 32.6 & 32.6 & 3 \\
\hline GBE & 1410 & 6.3 & 10.9 & 13.9 & 15.2 & 16.0 & 16.9 & 20.0 & 22.3 & 25.2 & 26.2 & 26.6 & 27.3 & 33.7 & 67.5 & 85.3 & \\
\hline & & & 10.1 & 11.8 & 13.5 & 15.0 & & 22.2 & 24.4 & & 28.6 & 9.0 & 9.2 & & & 2.8 & \\
\hline DTX & & 8 & 6.2 & 7.9 & 9.4 & 10.3 & & 11.6 & 12.0 & 12.6 & 14.0 & 3.4 & 16.1 & 28.1 & 4.8 & 0.4 & \\
\hline 7 & & & 8.9 & 13.0 & 14.7 & 15.7 & & & 24.5 & 27.6 & & & & & & 4.5 & \\
\hline & & 7.0 & 10.1 & 13.2 & 14.5 & 15.3 & 17 & 22.9 & 25.2 & 28.0 & 31 & .6 & 30 & 39 & & 3.6 & \\
\hline IC & & & 9.4 & 13.4 & 15.4 & 16.7 & 17 & 20.4 & 25.3 & 29.0 & 29 & .0 & 31 & & & & \\
\hline SAGR & 141096 & 5.9 & 11.0 & 14.3 & 15.5 & 16.8 & 18.8 & 22.2 & 25.0 & 27.9 & 28.9 & 29.4 & 29.7 & 37.6 & 76.2 & 93.8 & \\
\hline AGB & & & & 8 & 10.2 & 12.3 & & & 18 & 15 & .9 & & .3 & & & 7.8 & \\
\hline & & & & 12.2 & 15.5 & 17.4 & & & & 20.5 & & & & & & 3.9 & \\
\hline $\mathrm{G}$ & & & & 7.7 & 8.7 & 10.2 & & & 13.5 & 14.4 & 16.1 & & 20.1 & & & 5.2 & \\
\hline & & & 6 & 9.0 & 11.8 & 14.7 & & & & 19.8 & 21 & & 3.4 & & & 0.8 & \\
\hline & & & 4 & 6. & 7.7 & 8.6 & & 10.2 & 10.9 & 11.7 & 12 & & 5.9 & 26 & & 8.8 & \\
\hline $3 \mathrm{~A}$ & & & 5 & 7. & 8.4 & 9.7 & & & 12.6 & 13.3 & 1. & & & & & 4.4 & \\
\hline & & & 7 & 9. & 12.1 & 14.5 & & & 19.8 & 21.4 & & & & & & & \\
\hline 0 & & & 4.0 & 5.0 & 6.1 & 7.1 & & & 8 & 9.3 & 9.9 & 1 & 10 & 19 & & 7.8 & \\
\hline DEF & & 7. & 10.5 & 13.2 & 15.7 & 17.6 & & 9.7 & 20.4 & 21.5 & 22.6 & 3.7 & 5.5 & 34.3 & & 0.4 & \\
\hline $\mathrm{I}$ & & & 5.8 & & 8.0 & 9.4 & & & & 12.3 & & 14 & & & & 1.8 & \\
\hline CC & & & 7. & 9. & 11.0 & 2.0 & & & 13.9 & 14.6 & 1 & .0 & 16.4 & 22.5 & 5.3 & 7.3 & 111 \\
\hline & & & 9.7 & 12 & 17.1 & & & & 26 & & 31 & & & & 9.2 & 8.0 & 134 \\
\hline SAGR & & 4.4 & 7.7 & 10.9 & 14.6 & 16.8 & 19.1 & 20.4 & 21.6 & 23.2 & 24.6 & 26.7 & 29.3 & 40.3 & 63.1 & 0.3 & 114 \\
\hline BARK & 030999 & 13.7 & 23.9 & 32.2 & 39.9 & 44.5 & 46.6 & 47.5 & 47.9 & 48.0 & 48.2 & 48.3 & 48.5 & 50.7 & 56.0 & 56.1 & 56 \\
\hline $\mathrm{AGCO}$ & & 12.6 & 23.1 & 31.0 & 37.9 & 43.7 & 49.1 & & 56.0 & 57.2 & 57.9 & 58.6 & 59.8 & 60.6 & 60.7 & 4.1 & 65 \\
\hline & & & & & & & & & & & & & & & & & \\
\hline & & & & & & & & & & & & & 55.4 & 56 & & & \\
\hline & & & 22 & 30. & 34.7 & & 40 & 41. & 42.6 & 43 & 43 & & 45.5 & 46.4 & & & \\
\hline & & & & & & & & & & & & & & & & & \\
\hline & & 14.5 & & 34.1 & 40.6 & 45.5 & & 52.2 & 54.3 & 55.4 & 56.0 & 56.6 & 57.3 & 8.3 & 8.3 & 0.1 & \\
\hline & & 12.9 & 23 & & 38.1 & & & & 49.5 & 49.8 & & & & & & & \\
\hline & & 8 & & & & & & & & & & & & & & & \\
\hline & & 11 & 20 & 24 & 28.8 & 35 & 41 & 47.1 & 50.8 & 54.7 & 56.8 & 57.9 & 58.6 & 0.0 & & & \\
\hline & & & & & & & & & & & & & & & & & \\
\hline & & 7.9 & 13.3 & 20.0 & 25.5 & 33.0 & & 41.5 & 45.9 & 50.9 & 54.0 & 56.0 & 57.5 & 60.0 & 60.0 & 2.8 & \\
\hline ROLI & 140999 & 9.5 & 16.8 & 22.7 & 26.9 & 34.5 & 40.6 & 43.9 & 46.1 & 48.8 & 52.1 & 52.4 & 52.5 & 53.5 & 53.5 & 53.5 & 102. \\
\hline AGTR & 150701 & 15.8 & 19.3 & 20.7 & 21.2 & 25.8 & 28.7 & 29.8 & 30.3 & 30.3 & 31.4 & 34.4 & 39.2 & 64.9 & 68.7 & 69.7 & 69. \\
\hline AGTI & 091001 & 25.7 & 33.2 & 33.2 & 35.0 & 35.0 & 35.0 & 35.0 & 35.0 & 35.0 & 35.1 & 35.1 & 35.1 & 41.9 & 41.9 & 42.8 & 43. \\
\hline
\end{tabular}

In bold, quantities that have exceeded the return period of 5 years.

5 years (Table II) for the typical synoptic scale durations of 12 and $24 \mathrm{~h}$ (Orlanski, 1975). The event 7 August 1996 (070 896) is clearly a local storm showing intensities with return period higher than 5 years only for durations of 5 and $10 \mathrm{~min}$, and event 9 October 2001 (091001) shows high intensities also for durations shorter than $1 \mathrm{~h}$, which can be considered to be typical of the atmospheric microscale. The rest of the events show high intensities for the typical durations of the meteorological mesoscale, i.e. between 1 and $12 \mathrm{~h}$. So, the event registered on 24 August 1995 (240 895), shows a very high value of the IP, 1.29 (Table III), and high intensities registered for a large range of durations between $20 \mathrm{~min}$ and $24 \mathrm{~h}$. Rainfall corresponding to 21 September 1995 (210995), shows a 
Table III. Intensity index calculated for each of the selected rainfall cases and return period of 5 years.

\begin{tabular}{|c|c|c|}
\hline Gauge & DDMMYY & $\operatorname{IP}(5)$ \\
\hline CANY & 290994 & 0.50 \\
\hline DEPU & 290994 & 0.59 \\
\hline COTX & 191094 & 0.77 \\
\hline MONT & 191094 & 0.74 \\
\hline AJNO & 240895 & 1.29 \\
\hline AJNO & 210995 & 0.79 \\
\hline AJUO & 210995 & 1.30 \\
\hline COTX & 210995 & 0.76 \\
\hline SAGR & 210995 & 1.10 \\
\hline CLAB & 070896 & 0.68 \\
\hline AGBE & 141096 & 0.64 \\
\hline AJNO & 141096 & 0.67 \\
\hline COTX & 141096 & 0.50 \\
\hline ELIZ & 141096 & 0.66 \\
\hline MONT & 141096 & 0.69 \\
\hline NICA & 141096 & 0.68 \\
\hline SAGR & 141096 & 0.67 \\
\hline AGBE & 031298 & 0.61 \\
\hline AGCO & 031298 & 0.65 \\
\hline AGTI & 031298 & 0.52 \\
\hline AGTR & 031298 & 0.57 \\
\hline AJSA & 031298 & 0.51 \\
\hline BARK & 031298 & 0.53 \\
\hline CANY & 031298 & 0.61 \\
\hline COTX & 031298 & 0.45 \\
\hline DEPU & 031298 & 0.75 \\
\hline ELIZ & 031298 & 0.54 \\
\hline FCCF & 031298 & 0.53 \\
\hline HEUR & 031298 & 0.80 \\
\hline SAGR & 031298 & 0.67 \\
\hline BARK & 030999 & 0.80 \\
\hline AGCO & 140999 & 0.90 \\
\hline AJSA & 140999 & 1.04 \\
\hline BARK & 140999 & 0.85 \\
\hline CLAB & 140999 & 0.79 \\
\hline CATA & 140999 & 0.84 \\
\hline COTX & 140999 & 0.89 \\
\hline FCCF & 140999 & 0.83 \\
\hline FISI & 140999 & 0.77 \\
\hline HEUR & 140999 & 0.90 \\
\hline MONT & 140999 & 0.82 \\
\hline NABI & 140999 & 0.80 \\
\hline ROLI & 140999 & 0.88 \\
\hline AGTR & 150701 & 0.88 \\
\hline AGTI & 091001 & 0.86 \\
\hline
\end{tabular}

clear mesoscale behaviour for AJNO, COTX and SAGR gauges, whereas for AJUO the calculated IP has a very high value, 1.30, due to the high intensities registered for the four durations representing each scale: $19.9 \mathrm{~mm}$ in $5 \min$ (return period $T \approx 25$ years), $79.7 \mathrm{~mm}$ in $1 \mathrm{~h}(T \approx$ 50 years) $91.2 \mathrm{~mm}$ in $2 \mathrm{~h}(T \approx 40$ years $)$ and $94.2 \mathrm{~mm}$ in $24 \mathrm{~h}$ (slightly below the $T=5$ years). The event corresponding to 14 September, 1999 (140999) shows mesoscale characteristics also for most of the gauges, whereas the index for AJSA results 1.04 and for three of the four representative durations the rainfall amounts are high: $16.9 \mathrm{~mm}$ in $5 \mathrm{~min}$ (return period $T \approx 10$ years), $66.1 \mathrm{~mm}$ in $1 \mathrm{~h}(T \approx 15$ years $)$ and $67.3 \mathrm{~mm}$ in $2 \mathrm{~h}$ ( $T \approx 7$ years).

The objective classification of the 45 cases shown in Table II has been done using the clusters analysis technique (Anderberg, 1973). The dendrogram resulted is shown in Figure 2. The first vertical line drawn (short solid line L1) intersecting the hierarchical tree divides group IV from the rest of cases. This group is constituted, as expected, by AJNO 24 August 1995 (240 895) and AJUO 21 August 1995 (210995), two cases presenting the highest values of the intensity index: 1.29 and 1.30 (Table III), showing high rainfall amounts for more than one scale. The event on 24 August 1995 (240895) has presented intensities over the threshold imposed of 5 year return period for the gauge AJNO, for a wide range of durations between $20 \mathrm{~min}$ and $24 \mathrm{~h}$, indicating an origin caused by mid and large scale meteorological processes acting together, as well as the events classified in group IV by Casas et al. (2004). In the rain event registered on 21 September 1995 (210995), as commented, the storm has presented high rain intensities for all durations between $5 \mathrm{~min}$ and $24 \mathrm{~h}$, depending on the gauge, showing its complex structure. Particularly, AJUO 21 September 1995 (210 995) exceeds the imposed threshold for an extremely wide range between $5 \mathrm{~min}$ and $12 \mathrm{~h}$, being the $24 \mathrm{~h}$ amount $94.2 \mathrm{~mm}$, a value very slightly below the $95.9 \mathrm{~mm}$ corresponding to the 5 year return period. Group IV is, therefore, constituted by the most complex storms, showing the joint action of processes corresponding to more than one of the meteorological scales.

Drawing a second vertical line (solid line L2, Figure 2), groups I, II and III have been obtained. Group I, as expected due to its clear time scale, is constituted by two storms registered on 7 August 1996 (CLAB 070 896) and 9 October 2001 (AGTI 091 001). All cases corresponding to the events 29 September 1994 (290 994), 14 October 1996 (141 096) and 3 December 1998 (031 298) (22 records) have been classified as a common group. As commented before, these events have a clear synoptic origin (group III). The 19 remaining cases constitute group II, most of them showing high intensities for mesoscale durations lower than $6 \mathrm{~h}$. Attending to the subdivision of group II (dashed line L3, Figure 2), subgroup IIA identifying small mesoscale consists of AJNO and COTX 21 September 1995 (210995) and all records corresponding to 3 September 1999 (030999) and 14 September 1999 (140999). Subgroup IIB, corresponding to large mesoscale, is constituted for all cases of 19 October 1994 (191 094) and 15 July 2001 (150701). An isolated case 21 September 1995 (SAGR 210 995) remains out of this sub-classification. Despite of its situation into group II, this case could be included into group IV due to its high intensity index, 1.10 (Table III) and its temporal characteristics showing high rainfall rates in the mid and large 


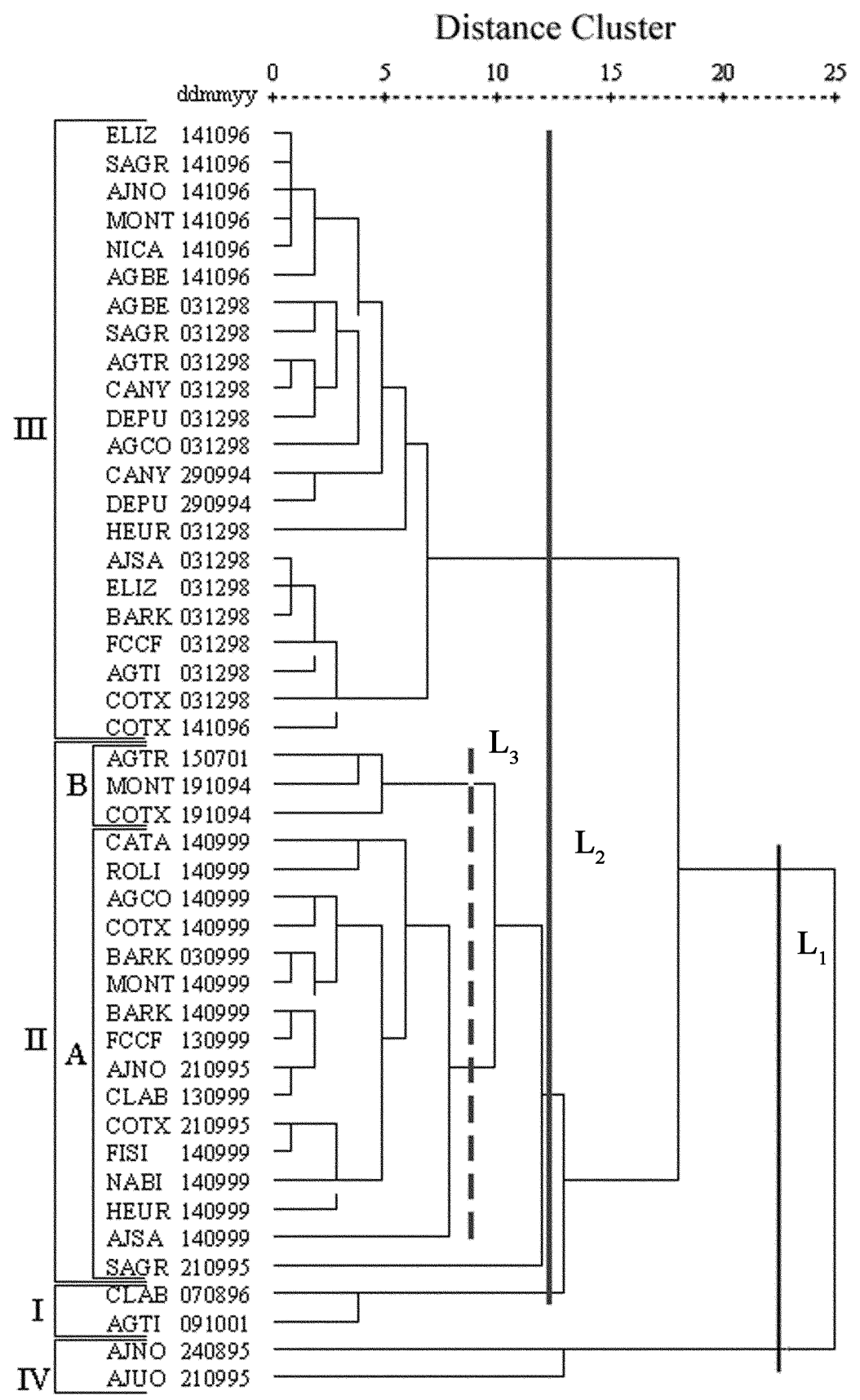

Figure 2. Dendrogram of the 45 rain cases selected.

scale (from 35 min. to $24 \mathrm{~h}$ ). Table IV shows the classification obtained.

Whereas the two microscale storms detected 7 August 1996, 9 October 2001 (CLAB 070896 and AGTI 091001 ) have only been registered by one gauge with amounts over the imposed threshold ( $T \geq 5$ years), the remaining events, specially those corresponding to synoptic scale (group III), have been registered by many gauges due to their larger spatial scale. It is noted that the synoptic rainfall which occurred on 29 September 1994 only appears to have been registered by two of the raingauges (CANY and DEPU 290994) because the rest were still not working.

The selected rainfall events registered by the rain gauge network have not the same distribution in groups than those registered by the Jardí gauge (Casas et al., 2004), due to the influence of the spatial scale of each group. For example, 8 of 44 selected events registered by the Jardí gauge (1927-1992) were local storms of group $\mathrm{I}$, the same ratio of $18 \%$ than the two storms among the 11 actual events registered by the urban network, but these two events have only been registered by one gauge with amounts over the imposed threshold of 5year return period, and therefore constitute only the $4 \%$ of the 45 cases of Table II. Similarly, synoptic events classified in group III were the $21 \%$ of the Jardí sample, a similar ratio than the $27 \%$ corresponding to the urban network ( 3 of the 11 actual events), but in this case, as a consequence of the repetitions recorded by several rain gauges for a same event, group III represents $49 \%$ of the 
Table IV. Classification of the 45 rain cases selected.

\begin{tabular}{|c|c|c|c|c|c|c|c|c|c|}
\hline \multicolumn{2}{|c|}{ Group I } & \multicolumn{4}{|c|}{ Group II } & \multicolumn{2}{|c|}{ Group III } & \multicolumn{2}{|c|}{ Group IV } \\
\hline & & \multicolumn{2}{|c|}{ IIA } & \multicolumn{2}{|c|}{ IIB } & \multirow[b]{2}{*}{ CANY } & \multirow[b]{2}{*}{290994} & \multirow[b]{2}{*}{ AJNO } & \multirow[b]{2}{*}{240895} \\
\hline CLAB & 070896 & AJNO & 210995 & MONT & 191094 & & & & \\
\hline \multirow[t]{21}{*}{ AGTI } & 091001 & COTX & 210995 & COTX & 191094 & DEPU & 290994 & AJUO & 210995 \\
\hline & & BARK & 030999 & AGTR & 150701 & AGBE & 141096 & SAGR & 210995 \\
\hline & & AGCO & 140999 & & & AJNO & 141096 & & \\
\hline & & AJSA & 140999 & & & COTX & 141096 & & \\
\hline & & BARK & 140999 & & & ELIZ & 141096 & & \\
\hline & & CLAB & 140999 & & & MONT & 141096 & & \\
\hline & & CATA & 140999 & & & NICA & 141096 & & \\
\hline & & COTX & 140999 & & & SAGR & 141096 & & \\
\hline & & FCCF & 140999 & & & AGBE & 031298 & & \\
\hline & & FISI & 140999 & & & AGCO & 031298 & & \\
\hline & & HEUR & 140999 & & & AGTI & 031298 & & \\
\hline & & MONT & 140999 & & & AGTR & 031298 & & \\
\hline & & NABI & 140999 & & & AJSA & 031298 & & \\
\hline & & ROLI & 140999 & & & BARK & 031298 & & \\
\hline & & & & & & CANY & 031298 & & \\
\hline & & & & & & COTX & 031298 & & \\
\hline & & & & & & DEPU & 031298 & & \\
\hline & & & & & & ELIZ & 031298 & & \\
\hline & & & & & & FCCF & 031298 & & \\
\hline & & & & & & HEUR & 031298 & & \\
\hline & & & & & & SAGR & 031298 & & \\
\hline
\end{tabular}

45 cases. The effect of the repetitions is not so notable in group II and IV, where rain events corresponding to the mesoscale were $50 \%$ of the Jardí selection, whereas the cases corresponding to the four rain network events clearly classified as mesoscale storms, together with some of the records of the complex storm of 21 September 1995 (210995), have yielded $40 \%$ of the 45 cases. The percentages corresponding to group IV were $11 \%$ for the Jardí selection and $7 \%$ for the network selection.

Despite of these different distributions in groups, both selections show a very similar IP behaviour. Figure 3 shows the IP calculated for the 45 selected cases and $T=5$ years, with values between 0.4 and 0.6 for the synoptic scale cases, and higher than one for the three cases constituting group IV. In this figure the two samples of intensity indices calculated have been represented, the white ones corresponding to the rainfall events registered by the Jardí gauge (1927-1992), and black ones those calculated to the 45 cases registered by the urban network of CLABSA (1994-2001).

A fitting of the two samples of indices using the lognormal standard distribution function (3) has been essayed:

$$
f(x)=\frac{1}{x \sigma \sqrt{2 \pi}} e^{-\frac{1}{2}\left(\frac{\ln x-m}{\sigma}\right)^{2}}
$$

$x$ being the statistic variable representing indexes IP, whereas $m$ and $\sigma$ are the mean and the standard deviation of the distributions ( $\ln x$ ) obtained from the logarithm

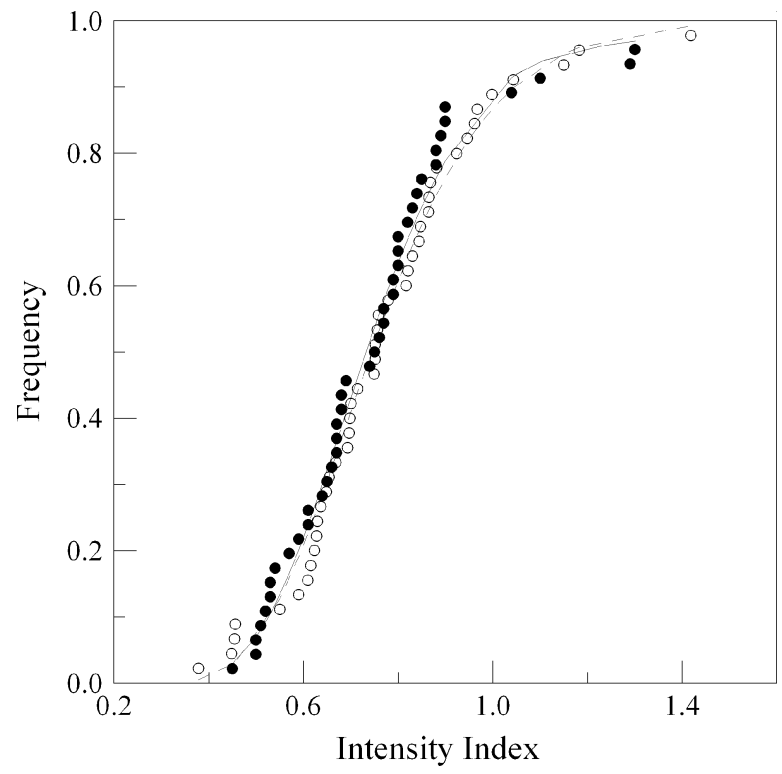

Figure 3. Intensity index values calculated for every storm selected and return period of 5 years. In white, storms registered by the Jardí gauge (1927-1992). In black, rain cases registered by CLABSA (1994-2001). The solid line is the lognormal distribution fitted to the CLABSA sample. The dashed line corresponds to the Jardí sample.

of the indices. Mean $m$ is the scale parameter of the lognormal distribution and $\sigma$ is the shape parameter. Their estimated values for the two fittings essayed are shown in Table V. Figure 3 shows these fittings also.

The results show the similar behaviour of the two samples of indices. With respect to the severity measure 
Table V. Fitting parameters $m$ and $\sigma$ calculated for the two data sets of intensity index IP. Number of cases $n$.

\begin{tabular}{cccc}
\hline & $m$ & $\sigma$ & $n$ \\
\hline IP (1927-1992) & 0.7444 & 0.2651 & 44 \\
IP (1994-2001) & 0.7323 & 0.2574 & 45 \\
\hline
\end{tabular}

and distribution of the extreme rain events in the zone, the sample of the 45 selected cases registered by the urban network in 8 years (1994-2001) seems to be almost equivalent to the sample of 44 events from the Jardí gauge in 66 years $(1927-1992)$.

\section{Conclusions}

From the records of the rain gauge network supported by CLABSA in Barcelona in the period 1994-2001, the maximum rain precipitation for durations between $5 \mathrm{~min}$ and $24 \mathrm{~h}$ have been calculated. Extreme storms presenting a return period equal to or higher than 5 years for any of the durations considered have been selected. The selection has resulted in 45 rain cases corresponding to 11 real storms registered for several of the gauges of the rain network. These cases have been satisfactorily characterized and classified into four clearly differentiated groups using the cluster analysis technique. The first group contains highly intense storms with very short durations (equal or shorter than $15 \mathrm{~min}$ ), representing the local rainfall events showing a clear seasonal influence and diurnal cycle. The second group corresponds to the typical mesoscale durations related to very active fronts moving slowly, where intense rainfall rate systems or mesoscale convective systems have been developed. The seasonal influence in this case is also clear. Synoptic rainfall events, with intensities exceeding the 5 year return period level only for the 12 and $24 \mathrm{~h}$ time interval, constitute the third group. Finally, a rainfall pattern showing high rates for large ranges of duration, associated to different scales acting together, has been found.

An Intensity Index, IP, taking into account the maximum rainfall in the $5 \mathrm{~min}, 1,2$ and $24 \mathrm{~h}$ time intervals has been calculated for every of the rain cases considered. This index reflects the contribution in the storm origin of local, mid and synoptic scale meteorological processes, and could be a measure of the severity and complexity of the observed rain. The calculated values of IP range from 0.4 to 0.6 for storms belonging to the synoptic scale, till values higher than one for the rain cases classified into group IV of the storms with small structures embedded in larger formations, such as mesocale organizations embedded into synoptic systems.

\section{Acknowledgements}

We gratefully acknowledge to Clavegueram de Barcelona S. A. (CLABSA) and the Observatori Fabra of Barcelona for providing us with the rain data used in this work.

\section{References}

Anderberg MR. 1973. Cluster Analysis for Applications. Academic Press: New York; 359 pp.

Burgueño A, Austin J, Vilar E, Puigcerver M. 1987. Analysis of moderate and intense rainfall rates continuously recorded over half a century and influence on microwave communications planning and rain-rate data acquisition. IEEE Transactions on Communications COM-35(4): 382-395.

Burgueño A, Codina B, Redaño A, Lorente J. 1994. Basic statistical characteristics of hourly rainfall amounts in Barcelona (Spain). Theoretical and Applied Climatology 49(3): 175-181.

Casas MC, Codina B, Redaño A, Lorente J. 2004. A methodology to classify extreme rainfall events in the western Mediterranean area. Theoretical and Applied Climatology 77: 139-150.

Eicher C. 1991. Selection of design storms-time resolution considerations. Atmospheric Research 27: 23-43.

Enjamio C, Vilar E, Redaño A, Fontán FP, Ndzi D. 2005. Experimental analysis of microscale rain cells and their dynamic evolution. Radio Science 40: RS3015, DOI:10.1029/2004RS003119.

Krajewski WF, Ciach GJ, Habib E. 2003. An analysis of smallscale rainfall variability in different climate regimes. Hydrological Sciences Journal 48: 151-162.

Lanza, L, Leroy, M, Alexandropoulos, C, Stagi, L Wauben, W. 2006. WMO Laboratory intercomparison of rainfall intensity gauges. Report 84, WMO/TD Number 1304. World Meteorological Organization, WMO: Geneva.

Lorente J, Redaño A. 1990. Rainfall rate distribution in a local scale: the case of Barcelona City. Theoretical and Applied Climatology 41: 23-32.

Lorente J, Redaño A. 1991. Relation between maximal rainfall rates for different time intervals in the course of a storm. Atmospheric Research 27: 61-66.

Orlanski I. 1975. A rational subdivision of scales for atmospheric processes. Bulletin of the American Meteorological Society 56: $527-530$.

Sevruk B, Ondrás M, Chvíla B. 2009. The WMO precipitation measurement intercomparisons. Atmospheric Research 92: 376-380.

Sumner GN. 1978. The prediction of short-duration storm rainfall intensity maxima. Journal of Hydrology 37: 91-100.

Villarini G, Mandapaka PV, Krajewski WF, Moore RJ. 2008. Rainfall and sampling uncertainties: A rain gauge perspective. Journal of Geophysical Research 113: D11102, DOI:10.1029/2007JD009214.

World Meteorological Organization. 1986. Manual for estimation of probable maximum precipitation. Operational hydrology. Report No.1. WMO-No.332, 269 pp. 